\title{
Research on the Development of Nanchang Tea-Picking Opera in Multidimensional Orientation
}

\author{
Qing Zhang ${ }^{1, \mathrm{a}}$ and Xiaorong $\mathrm{Li}^{2, \mathrm{~b}}$ \\ ${ }^{1}$ Lecturer of Art Institute of East China University of Technology, Nanchang, Jiangxi Province, \\ China \\ ${ }^{2}$ Jiangxi Institute of Economic Administrators, Nanchang, Jiangxi Province, China \\ a 406589470@qq.com, b 113225924@qq.com
}

\section{Keywords: Nanchang; Nanchang Tea-picking Opera; Opera; Broadway Opera; Cultural Tourism}

\begin{abstract}
In the context of the rapid development of the Internet, the international audio-visual, the integration of various media, the emergence of new thinking are constantly filling people's lives. Along with the rapid increase of public aesthetic ability, cultural and artistic products are becoming various and commercial to meet the secular, comparing to which, the opera market continues to cringe and niche. In this context, this paper aims to provide some new ideas for the development of Nanchang tea-picking operas. Through a large number of literature collected and questionnaire surveys and on the basis of long-term observation, this paper compares the development status of other sister arts at home and abroad to help them find their own limitations. The paper explores various ways for the tea-picking opera in Nanchang under the historical development of local culture. While enhancing its internal strength, it broadens its horizons and unifies all kinds of external forces and actively develops synergies with different industries. However, due to the author's limited knowledge, many ideas are not thoughtful, please forgive it. It is hoped that we can explore and study together with those who love tea-picking in Nanchang to create a place for this old Nanchang native opera art to get out of the woods and create a new world with its own characteristics.
\end{abstract}

\section{Introduction}

As a local opera for hundreds of years, the opera language and the music style of Nanchang TeaPicking Opera inherit many features of Nanchang native dialect tone, and the repertoire scenes are mostly about the local customs. After continuous refining, completing and evaluating, Nanchang Tea- Picking Opera spreads until now. At first, the performance of Nanchang Tea- Picking Opera was very simple, which was only three people performed tea picking and tea making processes. It has now gradually developed into a comprehensive form of opera which shows a rich story content and a certain ideological content by many people with the accompaniment of erhu, flute, suona, drum and other musical instruments ${ }^{[1]}$.

Founded in 1953, Nanchang Tea-Picking Opera Troupe was once the most influential local opera group of the audience both in Jiangxi Province and all over the country. It can be said to be the leading unit of Nanchang Tea-Picking Opera. In the spring of 2003, Taozhiyaoyao which was performed by the troupe was adapted into TV series Taohuayun. At the end of 2004, invited by Macau Chinese National Association, Nanchang Tea-Picking Opera Troupe performed in Macau. In 2006, the repertoire Yangmai of the troupe went to Germany, France, Belgium, Luxembourg and other countries with Nanchang Art Troupe, which was warmly welcomed and got a high rating. Yangmai was also published in the form of CD. [2]

In recent years, first,due to Nanchang subway construction, the building of Nanchang picking tea troupe was demolished. The troupe has no place for performance rehearsal, which has brought a lot of obstacles. Secondly, the age gap is extremely serious. There is not a single actor in the troupe who was born in the 1980s. At the same time, there are not enough actors and staff in the troupe to finish and mine the outstanding traditional repertoires. In addition, in this era when the market competition is intense and the role of publicity is significant, the management staff of the troupe are 
basically the actors on the stage and there is no independent publicity planning team. The troupe still relies on mouth-to-mouth spread when it has new performance or other news. There is no special website or WeChat public account and there is only a little information about the troupe in many searching engines.

In Sanjiaping, which was created by Nanchang Tea-Picking Opera Troupe in 2016, a large stage real scene was used. Gorgeous lighting sound added a lot of charm and beauty for the new repertoire. To enrich people's cultural life, Nanchang Municipal Government held "City Theater" for many times when Sanjiaping was brought to the audience. Although Nanchang City Art Museum is very far from the city center, there were still many people who went to watch the show and spoke highly of it. After the performance, a questionnaire survey of 587 audiences aged from 18 to 76 who loved tea-picking in Nanchang found that the public believed that the factors that affected the development of tea-picking opera in Nanchang presented the following data:

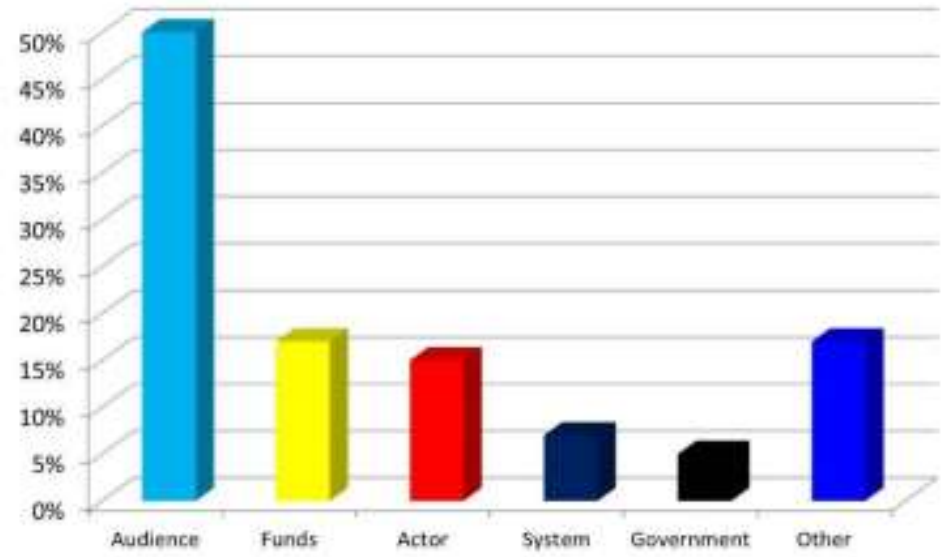

Beyond that, Music on Tengwang Feast which is on show at Tengwang Pavilion of Nanchang is hosted by Jiangsu Performing Arts Company. A part of the show is performed by the actors of Nanchang Tea-Picking Opera troupe. However, the show is not special repertoire of Nanchang Tea-Picking Opera, but the combination with Kunqu Opera. As an ordinary member who is engaged in the study of the local national opera, the author is deeply confused by this series of phenomena and cannot help thinking. As an ordinary member who is engaged in the study of the local national opera, the author is deeply confused by this series of phenomena and cannot help thinking.

\section{Management under Government Support}

To continue to develop, Nanchang Tea-Picking Opera must adapt to its cultural mission, at the same time, it shall do a good job in market positioning and clear the identity in the market. On the one hand, the government shall give a certain amount of support and protection, making Nanchang Tea-Picking Opera can effectively play its public rationality in the cultural market and reflect its value of cultural heritage in its development process. On the other hand, if there is no market or audience, the vitality of any form of art is extremely limited. So the spirit of the property and business attributes of Nanchang Tea-Picking Opera shall be coordinated. At the same time, the showing ways of Nanchang Tea-Picking Opera shall be different in different occasions and for different audiences. All the above shall be an urgent need to consider for any performance team of Nanchang Tea-Picking Opera. What's more, on their own management, the communication with the government leadership shall be properly carried on and the initiative and multi-contact shall also be taken referring the dynamic changes in the market to seek common development. Nanchang Tea-Picking Opera is a local cultural industry. It will be necessary and helpful for the specialized management, planning team assistance in addition to the performance of the team to understand the spiritual product market, circulation, consumption and other links. For example, Nanchang Tea-Picking Opera troupe does not take profit as the main goal, but it is still necessary to calculate the costs and losses. On the basis of the formulation of cultural and artistic policies, it is necessary 
for the government to increase capital investment. The costs of actor wages, sound, choreography and other daily expenses, the new repertoires, as well as publicity are required. However, the current low price cannot maintain the benign development needs of the troupe. With help of the government's policies and funds, the internal and external affairs shall be reasonably arranged and coordinated with multi-way and new concepts, to make Nanchang Tea-Picking Opera performing arts market can joint different industries. The management departments shall cooperate, consult and integrate actively with social enterprises. In addition to the promotion of their own development, the professional tea-picking culture management team shall consider, coordinate and carry out to create more high-quality cultural products to meet the spiritual needs for the audience of different groups and different levels.

\section{Expand the Vision to Re - establish the Concept}

The development of any kind of art is based on the spread to be better inherited. We always think that Chinese operas are only concerned and loved by middle-aged people. Nanchang Tea-Picking Opera is no exception. So the Chinese opera art is identified as the lack of market in the subjective. According to the tracking statistics after the consecutive shows of Sanjiaping, the attendance rate was about $70 \%$ and the audience was indeed elderly people and children. According to the data of Broadway, the average age of the local audience of musical shows is about 42 years old, and in the long-term follow-up survey, the average age is younger before. In other words, the audience of the United States Broadway musical which is such a famous commercial representative was not young people.

From the international point of view, whether the new generation or the traditional form of art, the long-term development cannot be judged by the amount of audience for a short time. The new development always hides in the crisis which can guide new movements. People have to change their old concept that the traditional Chinese opera is outdated, only in which way can Nanchang Tea-Picking Opera be advanced to a new stage. The United States Broadway survey data shows that the local audience accounts about $35 \%$ of the total audience, while visitors account for $65 \%$ in which a large part is the people who enter the theater for the second time and about $62 \%$ is the people who watch two shows in a performance season. From this statistic, we can see that there are $6 \%$ of the audience who watch more than 15 shows in a performance season and the tickets they purchase account for $35 \%$ of the total ticket sales. [3] It can be seen from the above statistics that constant support, especially local enthusiasts and tourists, is necessary for the development of an art form. Currently, the first need of Nanchang Tea-Picking Opera is to lead people to know and understand, and then like and love the traditional Chinese opera.

The tea-picking opera in Nanchang will keep its development in this era and must be adapted to its cultural mission. At the same time, it should make a good market positioning and clarify its identity in the market where it is located. This is very important for its own development. On the one hand, the government gives some support and protection, making the tea-picking opera in Nanchang can effectively exert the connotation of its public reason in the cultural market and embody the value of her heritage of culture in the process of its development. On the other hand, if there is no market and no audience, the vitality of any kind of art is extremely limited. Therefore, it is necessary to reconcile the spiritual attributes and commercial attributes of the tea-picking opera in Nanchang. At the same time pay attention to in different occasions, different audiences in front of the way and appearance. There is an urgent need for any team in Nanchang tea-picking opera. On the other hand, as far as its own management is concerned, on the one hand professional management and planning teams must be able to upload and communicate well with the government leading departments while constantly observing the dynamic changes in the market and actively approaching with various parties to seek common development, understand their spiritual products in the market, circulation, consumption in all aspects of their own homework, so that Nanchang tea opera, as a local cultural industry, can operate in a cycle. 


\section{Adjust the State to Carry Out the Multi-industry Joint Development}

In diversified society, any format cannot rest on its laurels and carry out its business alone in the form of small workshop. Based on its own advantages, combining with sociology, anthropology, history, psychology, economics and management points of view, the current difficulties shall be studied comprehensively and the new path which is suitable for the local development shall be searched for.

As the organizational core of Nanchang Tea-Picking Opera, this troupe has no fixed performance place. So it is difficult to form a place where the local Nanchang people can sing and talk about the opera together and it is also difficult to form a group of high-qualified fans which will be one of the key driving force to directly drive the development of Nanchang Tea-Picking Opera. A good fan group cannot only bring some benefits to the box office, while the younger generation of audience driven by this group will also help to reserve new actors and audience for Nanchang Tea-Picking Opera. As a decline industry and a member of the education industry, Nanchang Tea-Picking Opera actually has a very good prospect. Based on Nanchang local dialects and folk customs, Nanchang Tea-Picking Opera can take the troupe as the core and build a good place for the local people to listen to, learn, sing and talk about the opera after meals. China's population aging is increasingly serious. Along with the rapid rise of the national economy, besides food and clothing, people pay more attention to the quality of life and the spirit. The popularity of Putonghua changed the language habits of local people. From the psychological point of view, the older the people are, the more needs they return to the source. Nanchang Tea-Picking Opera is the only local opera which uses Nanchang local dialect. Nanchang Tea-Picking Opera has responsibilities to show Nanchang local dialect, inherit Nanchang local cultural characteristics and disseminate Nanchang culture. In Nanchang Tea-Picking Opera, "chi" is pronounced as "qi" and "shuo" is pronounced as "wa". "Li" which is the commonly used name affix is also used in this opera. In addition, "sha", "lei", "bo" and "luo" are also the words which are full of Nanchang characteristics. [4] There are many local dialects both in sung parts and spoken parts of the male "Chou" character, which has strong regional atmosphere, strengthens the character and pulls the distance between the actors and the audience . To support the development of fans is also a very important part of the development of Nanchang Tea-Picking Opera. At the same time, the troupe can set up different classes for amateur training specifically for the elderly and children. The classes can be divided into different training aspects, such as singing, figure, stage performance or instrumental music and other courses. Being different from the general music training courses, during the training process, the essence of Chinese opera and excellent parts of Nanchang Tea-Picking Opera will be chosen as course materials. The opera selections will be arranged according to levels, which will be taken as teaching materials for promotion. At the end of each season, some outstanding students will be chosen to perform on state. Some modern operas can also be created for discussion between actors and fans. In fact, during the process of acting, teaching and rehearsing, actors have grown, talents have been reserved and Nanchang Tea-Picking Opera has developed. The whole process is also to create an excellent Nanchang Tea-Picking Opera.

Recently, it is said that Nanchang Government is planning to move Nanchang Tea-Picking Opera troupe back to the origin place in Wanshou Palace antique style cultural neighborhood. The origin location is near Tengwang Pavilion, one of the four famous buildings of South China and it is also beside Guangrunmen, Wanshou Palace and other places which are commonly seen in traditional repertoires of Nanchang Tea-Picking Opera. The four famous repertories of Nanchang Tea-Picking Opera, Nanguaji, Gujiaji, Mingyuanji and Huajiaoji, are all based on true stories, in which there are many scenes which happened near here [5]. The troupe can cooperate with the local tourism department to create a series of tourism projects with Nanchang local cultural style. Visitors can "listen to Tea-Picking Opera and watch Wanshou Palace, drink tea and watch Tengwang Pavilion". Now there are many new attractions. The garden-like pavilions reproduce the classical style of Chinese architecture that "natural landscape afforestation" in visual, However, to create a cultural area cannot only focus on the new construction of pavilions without spiritual and cultural connotation. Most of the domestic attractions are similar or even repeated. For foreign tourists, to 
understand the local customs through Nanchang Tea-Picking Opera will be an extremely important part in humanity tourism and opera tourism which meets people's spiritual needs in the economically developed era. Compared to the static form of art, the cultural impression of Nanchang Tea-Picking Opera on people will be more direct, vivid and acceptable.

To search for local fans and foreign tourists, it will be necessary to make diversification in repertoire arrangements, performances and other aspects. For example, the same play can be arranged multiple versions, taking into account the needs of different audiences, effectively combining with different occasions and the needs of targeted audience. Actors of different ages can act the original play. For the short play, actors of middle-age and the youth can act the famous and essence parts. The single Tea-Picking musical can be arranged the instrumental show. Try multi-version of the acting forms and enrich the opera playing styles. The repertoires of Tea-Picking Opera can be put in different occasions, in addition to the professional theaters, but also some of the traditional classic landscapes. So that audience can taste food at the same time when enjoying Nanchang local tea and opera culture. Integrating the linkage of the transmission, to bring audience enjoyment from history, culture, art and other aspects. At the same time, Nanchang Tea-Picking Opera which comes from the folk shall return to the countryside and the city's urban cultural activities. In response to the call of the cultural department of Nanchang, the shows organized by the government are welcomed in communities during festivals, which enriches the spiritual life of people, so that more people can enjoy the cultural feast.

\section{Pay Attention to Internal Strength Practice and all Aspects of Upgrading}

Talent training is important of the development of any kind of opera. In addition to the introduction of talent from the professional institutions, to conduct a joint school with professional institutions is also very important. For example: Nanchang Tea-Picking Opera troupe jointly carried out professional performance classes in 2009 with Jiangxi Art Vocational College [6]. Opera art is a comprehensive art which is a set of singing, speaking, acting and dancing. A solid foundation needs long-term training. At the same time, due to the current phenomenon that the age gap of the actors in Nanchang Tea-Picking Opera troupe is very serious that the young actors were born in 1990s, it is necessary to invite maters from multi-channel for lectures to improve the professional qualities of the existing actors. In addition, actors shall be sent to study regularly. Personal performance shall also be held at regular intervals. The qualities and abilities of actors can be improved in this performance and study.

Because of the convenience of the Internet, people are more like experiential and interactive entertainment learning leisure way. [7]Nanchang Tea-Picking Opera has to re-start and produce new repertoires under new concepts, which is essential. In the Information times, the processes of searching and creating can be participated by the public.Then the moving stories of Nanchang people can be found, The writers writing according to the characteristics of Nanchang tea picking opera. A good story is the core of a play, and often the most touching story is rooted in people's lives. In addition, for the traditional Tea-Picking Opera, the aesthetic ideas and aesthetic tastes of different periods will be different with the change of the times. The previous traditional repertoires need organizing and excavating with a new concept to create new ones. Another important:Actors' performance and singing gradually progress, the accompaniment of music gradually enriches and the clothing and furnishings are carefully crafted. All the above contains the re-understanding of the opera of all the staff. With the efforts of everyone, the opera can be interpreted to adapt to the times with innovation and changes. [8]

At the same time, Tea-Picking Opera shall be actively promoted on campus, which will play an important role on the protection of the opera. Firstly, the relevant government departments shall support Nanchang Tea-Picking Opera to be brought in the universities and colleges of Nanchang as elegant music. In addition, the relevant lectures and academic seminars, as well as free courses shall be carried out on campus. In universities and colleges, many young people have high cultural literacy, strong acceptable ability and wide spread ability. Zhang Longzhi, the composing teacher of Nanchang Tea-Picking Opera troupe, talked about the development process, music singing, the 
spoken parts and other theoretical knowledge and carried out a series of activities in Nanchang University of Aeronautics and Astronautics. He also performed some pieces of the Tea-Picking Operas which were welcomed by students [9]. In addition, it is very important to let the primary and secondary school students access to Tea-Picking Opera. All countries focus on education and heritage of their traditional music arts in the basic education. At present, the situation of Chinese opera culture and the speed of economic development is very disproportionate. Contents relating to Nanchang Tea-Picking Opera shall be included in the local compulsory teaching materials while organizing the appropriate Nanchang Tea-Picking activities, so that young people can understand Nanchang Tea-Picking culture, which is necessary for the heritage of local opera.

\section{Conclusion}

The government support from policy and economy, the positive guide of the media, as well as the joint efforts of the people who are engaged in this opera are all indispensable of the inheritance and development of Nanchang Tea-Picking Opera. Nanchang Tea-Picking Opera narrates the cultural traditions and the historical stories of Nanchang people by their local opera accent. It inherits the local culture and art and communicates with the people all over the world with its unique way. On the one hand, the identity of the cultural awareness of Nanchang Tea-Picking Opera shall be established to help it be out of difficulty, which is the common responsibility of the local people. On the other hand, to appeal to all, Nanchang Tea-Picking Opera shall create a vast world for Nanchang, the capital of Jiangxi Province, from the aspect of culture.

\section{References}

[1] Study on the Development and Cultural Connotation of Tea - picking Drama [D]. Nanchang: Nanchang University dissertation, Hu Bo, 2012, p.17 (In Chinese)

[2] Explore the Source of Tea-Picking Tea in Nanchang [J], Beijing: New Operas, Liu Xiaoyan, 2016-12. p.33 (In Chinese)

[3] Volume I of Art Management Studies [M]. Nanjing: Southeast University Press Liu Weidong, 2012. p.258.(In Chinese)

[4] [5] Source of Nanchang Tea-Picking Opera [G]. Nanchang: Nanchang Tea-Picking Troupe Information, Zhu Liangcheng, 2013. (In Chinese)

[6] Analysis of the Music Components of Nanchang Tea-Picking Operas -Take "Pumpkin" as an Example [J]. Fuzhou: Fujian Tea, Zhou Xiaolu, 2015-12. (In Chinese)

[7] On the Development of Nanchang Tea-Picking Operas [J]. Jiamusi: Jiamusi Vocational College Journal, Zhang Tao, 2016-07. p.27 (In Chinese)

[8] Tea-Picking Opera Rhyme [M]. Guangzhou: South China University of Technology Press, Yuan Shangda, 2014-05-01. p.156 (In Chinese)

[9] Source of Nanchang Tea-Picking Opera [G]. Nanchang: Nanchang Tea-Picking Troupe Information, Zhu Liangcheng, 2013. (In Chinese) 